\title{
Magnitude of Pharmacological Nonadherence in Hypertensive Patients Taking Antihypertensive Medication from a Community Pharmacy in Spain
}

\author{
Zeneida Perseguer-Torregrosa, PhD; Domingo Orozco-Beltrán, PhD; Vicente F. Gil-Guillen, PhD; \\ Salvador Pita-Fernandez, PhD; Concepción Carratalá-Munuera, PhD; Vicente Pallares-Carratalá, PhD; \\ and Adriana Lopez-Pineda, MSc
}

\begin{abstract}
BACKGROUND: The most common factor associated with poor control of hypertension is treatment nonadherence to antihypertensive drug therapy. OBJECTIVE: To measure drug nonadherence and associated factors in pharmacologically treated hypertensive patients.

METHODS: A prospective observational study was carried out from March 2007 to August 2009 at a community pharmacy in Spain. A pharmacist invited a convenience sample of hypertensive patients aged 50 years and older taking antihypertensive medication for at least 3 months prior to participate in the study. Drug nonadherence was analyzed by 3 separate methods: pill count, as the gold standard method, and Haynes-Sackett and Morisky-Green questionnaires. A descriptive analysis of drug nonadherence and variables associated with nonadherence was performed. Logistic regression models were used to determine the variables associated with nonadherence.
\end{abstract}

RESULTS: Data were recorded from 419 patients. The drug nonadherence ratio varied depending on the method used: $62.8 \%$ by pill count, $3.1 \%$ by the Haynes-Sackett self-report test, and $36 \%$ according to the Morisky-Green test. In the multivariate model, the variable associated with a decrease in drug nonadherence was years of known hypertension $(0 \mathrm{R}=0.962,95 \% \mathrm{Cl}=0.937-0.988)$, and the variables associated with an increase in drug nonadherence were loose-pill combination therapy versus fixed-dose combination therapy or monotherapy (OR=4.099, 95\% $\mathrm{Cl}=2.494-6.757)$ and good perception of quality of life $(\mathrm{OR}=1.276,95 \%$ $\mathrm{Cl}=1.109-1.471)$.

CONCLUSIONS: The magnitude of drug nonadherence varies depending on the method of measurement. The pill count method (reference method) revealed that 2 out of 3 patients with hypertension did not have good adherence. This study highlights the lack of antihypertensive drug adherence and the pharmacist's ability to detect the associated factors in order to find the best way to deal with nonadherence.

J Manag Care Pharm. 2014;20(12):1217-25

Copyright $\odot 2014$, Academy of Managed Care Pharmacy. All rights reserved.

\section{What is already known about this subject}

The most important factor associated with poor control of hypertension is treatment nonadherence.

The World Health Organization estimates that 50\%-70\% of people do not take their antihypertensive medications as prescribed. The magnitude of antihypertensive drug nonadherence in Spain ranges from $7.1 \%-66.2 \%$, and it is difficult to identify associated factors. The role of the pharmacist in the assessment of therapeutic adherence has been recognized.

\section{What this study adds}

The magnitude of therapeutic nonadherence is important because 2 out of 3 hypertensive patients in the study who visited the pharmacy were identified as noncompliant with antihypertensive drug therapy.

Antihypertensive therapy complexity and perception of a good quality of life were the variables associated with higher nonadherence; years of known hypertension was the variable associated with lower nonadherence.

The magnitude of drug nonadherence varies depending on the method of measurement: pill count (62.8\%), Haynes-Sackett test (3.1\%), and Morisky-Green test (36\%).

A rterial hypertension is one of the leading causes of morbidity, mortality, and disability in the world. ${ }^{1}$ More than 74.5 million Americans have hypertension, with an estimated cost of $\$ 76.6$ billion per year. ${ }^{2}$ The prevalence of hypertension in Spain is high, approximately 30\%-50\% (47\% men, 39\% women), and it increases with age (comparing groups aged $35-44$ years vs. aged $65-75$ years, $24 \%$ vs. $72 \%$ in men and $12 \%$ vs. $72 \%$ in women). 3,4

Hypertension control is an issue of great concern, and while it has improved, that improvement is still insufficient, around $50 \%,{ }^{4}$ and one of its ramifications is loss of quality of life (QoL). ${ }^{5,6}$ The most important factor associated with poor control of hypertension is treatment nonadherence. The World Health Organization (WHO) estimates that 50\%-70\% of people do not take their antihypertensive medications as prescribed. ${ }^{7}$ The magnitude of antihypertensive drug nonadherence in Spain ranges from 7.1\%-66.2\%, according to reviews by Puigventós et al. (1997) and Márquez et al. (2006)., 8,9

Numerous methods are used to assess patient compliance. Indirect measures of adherence are simple and economical, and they include various forms of self-reporting by the patient, such as medication measurement (pill count), compliance tests (Morisky-Green, Haynes-Sackett), ${ }^{10,11}$ use of electronic monitoring devices, and review of prescription records and claims. Pill count is considered the "gold standard" for measuring medication adherence. ${ }^{12}$ The Morisky-Green and the HaynesSackett tests are most often used in clinical practice because of their high specificity, simplicity, and brevity. 
Adherence is a complex process, and nonadherence has often been poorly defined. Patients' decisions about how to manage their medications are likely based on economic, physical, psychological, and social considerations. ${ }^{13}$ Identifying factors associated with adherence would be of value for health care providers in order to focus on strategies to enhance patient adherence to antihypertensive medications. Given the magnitude of nonadherence and its complexity, an interdisciplinary approach involving the pharmacist could add value to the overall treatment of patients. This interdisciplinary approach is a recommendation made by the $\mathrm{WHO}$, the American Society of Hypertension, and the International Pharmaceutical Federation. ${ }^{7,14}$

The purpose of this study was to measure adherence to antihypertensive medications assessed by a community pharmacist and to identify factors associated with nonadherence. The primary objective was to determine the extent of medication nonadherence in pharmacologically treated hypertensive patients who visited a specified community pharmacy. Secondarily, we identified associated factors of nonadherence to antihypertensive medications, such as sociodemographic and anthropometric characteristics, comorbidity, QoL, hypertensive and concomitant medication, years of known hypertension, and other general factors associated with therapeutic nonadherence.

\section{Methods}

\section{Scope, Study Period, and Recruitment}

This study was carried out in a community pharmacy in Petrer (Alicante) in southeastern Spain. The study design, data collection, and analysis took place between March 3, 2007, and August 14, 2009. This was an observational prospective study that used consecutive nonprobability sampling. The sample size was calculated, estimating the rate of nonadherence as $50 \%$, at a sampling precision level of $\pm 4.5 \%$ and $95 \%$ confidence interval (CI). Assuming a loss to follow-up of $8 \%$, at least 418 patients were needed.

As patients visited the pharmacy to collect their antihypertensive medications or to measure their blood pressure (BP), the community pharmacist explained the study to patients who met the inclusion criteria and invited them to participate. Patients included were hypertensive patients aged 50 years or older who were taking antihypertensive medication for at least 3 months and who visited the pharmacy during the study period and gave their informed consent to participate in the study.

Patients were excluded if they presented with dementia or severe diseases or any mental, pathological, or social issue that could prevent adequate completion of the data collection notebook or pill count. Also excluded were pregnant women, participants in other research studies, persons living with somebody else taking the same antihypertensive treatments, anyone with treatment distributed over several locations, and anyone who did not have a telephone contact number.

\section{Process}

Once patients were recruited, the initial visit and 2 follow-up visits were made. At the initial visit for each patient, a Case Report Form listing anthropometric characteristics, dietary habits, exercise, smoking, alcohol intake, and comorbidities was recorded. In addition, BP was measured in both arms, and the second visit was planned in 2-3 days by asking the patient to come back with all medications he or she had at home (not only for hypertension) to avoid mistakes, since some patients were not able to identify all medications for hypertension. The duration of the first visit was about 30 minutes. In the second visit, the medications were reviewed by counting the pills for each hypertensive medication that the patient had at home (count 1). BP was measured on the arm where BP was higher when it was measured initially, and the European Quality of Life (EuroQOL) test was completed. ${ }^{15}$ The duration of the second visit was about 45 minutes. The third and final visit was planned in 30 days from the second visit. In the third visit, the medications were reviewed by counting the pills for each antihypertensive medication that the patient had at home (count 2). $\mathrm{BP}$ was measured on the arm where BP was higher when measured at visit 1; a blood sample was taken for analytical variables; and the patient was asked about any new prescriptions or therapeutic changes in medication for hypertension (HTN). The patient was excluded if any change in the HTN medication had been made between the second and third visits. The Haynes-Sackett ${ }^{16}$ and Morisky-Green ${ }^{17}$ tests were then administered. The duration of the last visit was about 60 minutes.

\section{Measurements}

The study variables were as follows:

- Lifestyle: Salt consumption, smoking habit, alcohol consumption, and sedentary lifestyle. Salt consumption was defined as high if it was more than 5 grams per day (gm/ day). Smoking was defined as regular consumption of any kind of tobacco. Alcohol consumption was defined as taking more than $30 \mathrm{gm} /$ day in men and $20 \mathrm{gm} /$ day in women. Sedentary lifestyle was defined as an exercise (e.g., walking) less than 30-45 minutes 3-5 days a week. 18-20

- Demographic and anthropometric characteristics: Age, sex, weight, height, and body mass index (BMI). ${ }^{18}$

- Comorbidity: Diabetes, dyslipidemia, metabolic syndrome, obesity, cardiovascular risk, HTN, and other chronic diseases (e.g., chronic obstructive pulmonary disease, heart failure, atrial fibrillation, ischemic heart disease, depression). Comorbidity variables were measured according to a patient interview and medication prescribed. Metabolic syndrome and cardiovascular risk were calculated according to Spanish and European guidelines. ${ }^{21-23}$ Obesity was defined as a BMI > 30 kilogram per squared centimeter. ${ }^{18}$

- BP measurement: Mean systolic BP and mean diastolic BP. BP was measured 4 times (spaced 2 minutes apart) on 
each of the 3 visits using an Omron 705 CPII automated oscillometric upper arm sphygmomanometer, which was validated and calibrated in accordance with the protocols of the Spanish and European clinical practice guidelines. ${ }^{21-23}$ BP was taken according to the Spanish and European guidelines: 5 minutes at rest, back supported with feet flat on the floor; proper cuff size at heart level; refrain from drinking coffee or tea, smoking, or exercise at least 30 minutes prior to measurement. The average BP was obtained from the third visit, when white coat syndrome was reduced. ${ }^{24}$ The patients came in the morning fasting and without taking their antihypertensive medications in order to avoid the immediate effect of the pill. According to the European clinical practice ESH/ESC 2007 guidelines, BP control was defined as systolic BP (SBP) $<140$ millimeters of mercury $(\mathrm{mmHg})$ and diastolic BP (DBP) $<90 \mathrm{mmHg}$ for patients without diabetes, cardiovascular disease, or chronic kidney disease (CKD) and of SBP $<130 \mathrm{mmHg}$ and $\mathrm{DBP}<80$ $\mathrm{mmHg}$ for patients with diabetes or CKD. ${ }^{23}$

- Quality of life: QoL was determined using the EuroQol-5D (EQ-5D)health questionnaire. ${ }^{15}$ The EQ-5D measures the QoL of patients in 5 dimensions (mobility, self-care, daily activities, pain/discomfort, and anxiety/depression), each with 3 levels of severity (no problems [1], some problems [2], many problems [3]) where the minimum score is 5 (good $\mathrm{QoL}$ ) and the maximum score is 15 (very poor $\mathrm{QoL}$ ). The patients were subsequently categorized into 2 categories: (1) Good QoL-those with better scores in EuroQol-5D (5 points), which stands for no problems in every 5 dimensions-and (2) Poor QoL-the remaining patients who scored worse, for higher than 5 points.

- Therapeutic nonadherence: Three indirect methods were used to measure nonadherence.

1. Pill count. Initial pill count required the patients to bring their antihypertensive medications in their packaging. At the second and third visits, the pharmacist recorded the date and the number of tablets in each patient's possession. Thereafter, the number of tablets consumed from the initial count was calculated. For those cases in which the patient received additional packs of antihypertensive drugs, the new tablets were added to the initial count. The number of tablets that the patient should have consumed in the time between the 2 counts was calculated (number of days multiplied by the number of tablets prescribed per day). Finally, the percentage of adherence by the patient was calculated as follows:

$$
\begin{gathered}
\text { Percentage } \\
\text { of Adherence }
\end{gathered}=\frac{\text { Number of tablets consumed }}{\text { Number of tablets that }} \times 100
$$

Following Haynes et al. (1980), ${ }^{16}$ drug nonadherence was established as taking less than $80 \%$ of the prescribed pills. If the patient was taking multiple antihypertensive medications, the average percentage of adherence for every antihypertensive medication that the patient was taken at that moment was calculated.

In addition, at the final third visit, 2 more methods based on clinical interview were used: the Haynes-Sackett ${ }^{16}$ and Morisky-Green ${ }^{17}$ tests. In order to compare validity of each method, sensitivity, specificity, and predictive values were calculated by using pill count as the gold standard method.

2. Haynes-Sackett test. ${ }^{16}$ This is a self-reported test that asks the following question: "People often have difficulty taking their pills for one reason or another and we are interested in finding out any problems that occur so that we can understand them better." Patients were then asked whether they ever missed their pills and, if so, the patient was considered nonadherent to treatment.

3. Morisky-Green test. ${ }^{17}$ This is a self-reported test that asks 4 questions: (a) Have you ever forgotten to take your medicine? (b) At times, are you not careful about taking your medicine? (c) When you feel better, do you sometimes stop taking your medicine? (d) At times, if you feel worse when you take your medicine, do you stop taking them? Patients were considered nonadherent if they responded affirmatively to at least 1 question.

- Antihypertensive therapy complexity: Monotherapy (MONO) was defined as a treatment with a single drug; antihypertensive fixed-dose combination therapy (FDCT) was defined as a formulation including 2 or more active pharmaceutical ingredients combined in single dosage form, which is manufactured and distributed in certain respective fixed doses; and loose-pill combination therapy (LPCT) was defined as patients taking 2 or more active pharmaceutical ingredients separately, not in single dosage form.

\section{Statistical Analysis}

We performed a descriptive assessment of all variables included in the study. After determining the normality of the variables with the Kolmogorov-Smirnov test, the Student's t-test or Mann-Whitney test, as appropriate, was used to compare the means. The multiple comparisons of means were performed using analysis of variance (ANOVA) or the Kruskal-Wallis test. Correlation of quantitative variables was performed by calculating the Pearson's or Spearman's correlation coefficient. The association between qualitative variables was carried out using the chi-square statistic $\left(\mathrm{X}^{2}\right)$. Logistic regression models were carried out to determine the variables associated with nonadherence, taking into account those independent variables with significance in the bivariate analysis. The goodness of fit of the final model was checked out. The statistical analysis was done using IBM SPSS Statistics 19.0 (SPSS, Inc., Chicago, IL).

The project was approved by the Hospital Ethics Committee of the Department of Elda (Alicante, Spain), ensuring information confidentiality according to the Spanish Data Protection Law (15/1999). ${ }^{25}$ 


\section{FIGURE 1 Study Participants}

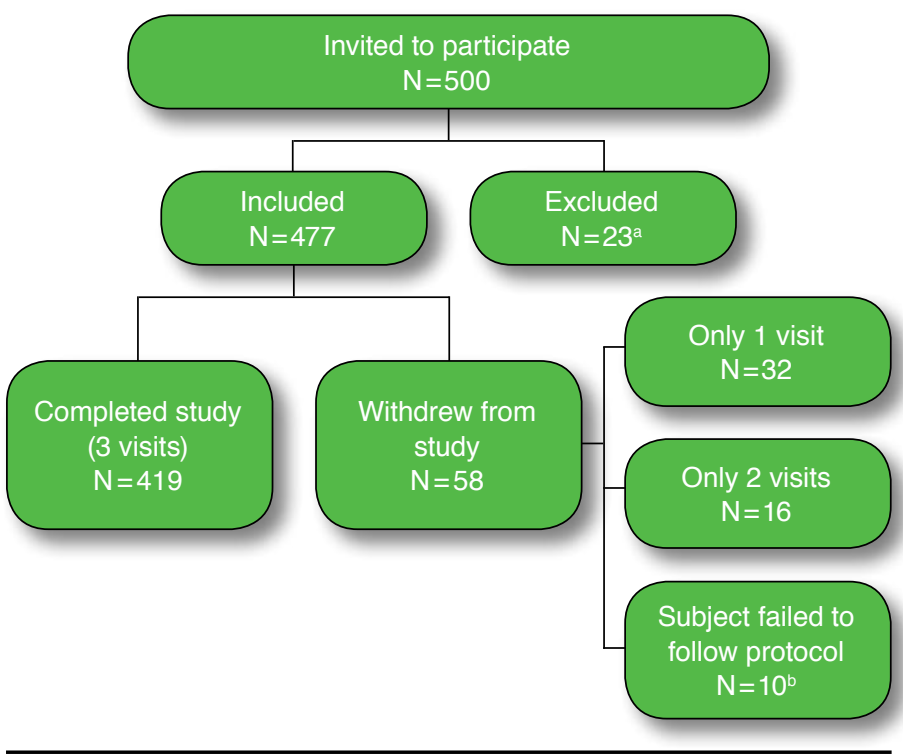

aReasons for exclusion $(n=23)$ : declined to participate $(n=7)$; patients with dementia or severe diseases or any mental, pathological, or social issues that could prevent adequate completion of data collection notebook or pill count $(n=7)$; participants in other research studies $(n=1)$; persons living with somebody else taking the same antihypertensive treatments $(n=5)$; anyone with treatment distributed over several locations $(n=2)$; and anyone who did not have a telephone contact number $(n=1)$.

${ }^{b}$ Reasons for failing to follow protocol $(n=10)$ : not bringing all antihypertensive medications that patient is taking $(n=8)$ and changes in antihypertensive drugs $(n=2)$

\section{Results}

A total of 419 patients were recruited. Figure 1 shows reasons why some patients were excluded and reasons for withdrawal. The baseline participation characteristics of patients are described in Table 1.

\section{Measurement of Nonadherence}

According to pill count, $62.8 \%$ (95\% CI=58.2-67.4) of the hypertensive patients were nonadherent (Figure 2). Only $3.1 \%(95 \%, C I=1.4-4.8)$ of the hypertensive patients reported nonadherence on the Haynes-Sackett self-report test (HST). According to the Morisky-Green test (MGT), 36\% (95\% $\mathrm{CI}=31.4-40.6)$ were considered nonadherent. In Table 2, the methods of measurement (HST, MGT) are compared with the reference test (pill count). The sensitivity of HST is very poor (3\%), as the specificity is very high (97\%). The MGT has low sensitivity (36\%) and slightly high specificity (63\%), but both validity indexes are lower than $80 \%$, a target to consider as a good index for screening.

\section{Variables Associated with Nonadherence}

According to the bivariate analysis of the study variables with pill count in the range of poor adherence $<80 \%$ and good

\section{TABLE 1 Baseline Participation Characteristics}

\begin{tabular}{|c|c|c|}
\hline Variables & Total $(n=419)$ & $95 \%$ CI \\
\hline Age (years), mean (SD) & $64.7(12.4)$ & $63.4-65.8$ \\
\hline Women, n (\%) & $235(56.1)$ & $51.3-60.9$ \\
\hline BMI $\left(\mathrm{kg} / \mathrm{m}^{2}\right)$, mean $(\mathrm{SD})$ & $31.3 \quad(5.4)$ & $30.8-31.8$ \\
\hline Total drugs, mean (SD) & $4.7 \quad(2.7)$ & $4.4-4.9$ \\
\hline Total pills, mean (SD) & $4.9 \quad(3.8)$ & $4.6-5.3$ \\
\hline \multicolumn{3}{|l|}{ Lifestyle, n (\%) } \\
\hline Salt consumption $>5$ gm/day & $326(77.8)$ & $73.8-81.8$ \\
\hline Smoking habit & $51(12.2)$ & $9.4-15.7$ \\
\hline $\begin{array}{l}\text { Alcohol consumption }>40 \mathrm{gm} / \text { day } \\
\text { (men) or } 23 \text { gm/day (women) }\end{array}$ & $14 \quad(3.3)$ & $2.0-5.5$ \\
\hline $\begin{array}{l}\text { Exercise (less than 30-45 min/ } \\
\text { 3-5 days/week) }\end{array}$ & $189(45.10)$ & $40.3-49.9$ \\
\hline \multicolumn{3}{|l|}{ Comorbid conditions, $\mathbf{n}(\%)$} \\
\hline Diabetes & $92(22.0)$ & $18.0-26.0$ \\
\hline Dislipidemia & $139(33.2)$ & $28.7-37.7$ \\
\hline Metabolic syndrome (ATPIII guideline) & $230(54.9)$ & $50.1-59.7$ \\
\hline Obesity (BMI > 30) & $229(54.7)$ & $49.9-59.5$ \\
\hline High CV risk $(\geq 20 \%)^{a}$ & $293(69.9)$ & $65.5-74.3$ \\
\hline $\begin{array}{l}\text { Patients with } 2 \text { or more chronic } \\
\text { conditions, } \mathrm{n}(\%)\end{array}$ & $369(88.1)$ & $85.0-91.2$ \\
\hline
\end{tabular}

Blood pressure

\begin{tabular}{|c|c|c|}
\hline Patients with good control, n (\%) ${ }^{\mathrm{b}}$ & $112(26.7)$ & $22.5-30.9$ \\
\hline Systolic blood pressure, mean (SD) & $142.3(21.6)$ & $140.2-144.4$ \\
\hline Diastolic blood pressure, mean (SD) & $80.2(10.1)$ & 79.9-81.1 \\
\hline Evolution of HTN (years) & $9.7 \quad(8.9)$ & $8.8-10.5$ \\
\hline Total HTN drugs, mean (SD) & $1.6 \quad(0.9)$ & $1.5-1.7$ \\
\hline Total HTN pills, mean (SD) & $1.6 \quad(1.0)$ & $1.5-1.7$ \\
\hline Total HTN active agents ${ }^{c}$ & $1.8 \quad(1.0)$ & $1.8-1.9$ \\
\hline \multicolumn{3}{|l|}{ Quality of life, n (\%) } \\
\hline $\begin{array}{l}\text { Good quality of life (5 points in } \\
\text { EuroQol-5D test) }\end{array}$ & $137(32.0)$ & $28.2-37.2$ \\
\hline \multicolumn{3}{|l|}{ Nonadherence, $\mathrm{n}(\%)$} \\
\hline Nonadherence, pill count $<80 \%$ & $263(62.8)$ & $58.2-67.4$ \\
\hline Nonadherence, Haynes-Sackett test & $13(3.1)$ & $1.4-4.8$ \\
\hline Nonadherence, Morisky-Green test & $151(36.0)$ & $31.4-40.6$ \\
\hline \multicolumn{3}{|c|}{ Antihypertensive therapy complexity, n (\%) } \\
\hline Monotherapy & $185(44.2)$ & $39.4-49.0$ \\
\hline Fixed-dose combination therapy & $69(16.5)$ & $12.9-20.1$ \\
\hline Loose-pill combination therapy & $165(39.4)$ & $34.74-44.1$ \\
\hline \multicolumn{3}{|c|}{$\begin{array}{l}\text { bood HTN control according to ESH/ESC } 2007 \text { guidelines: systolic blood pressure } \\
<140 \mathrm{mmHg} \text { and diastolic blood pressure }<90 \mathrm{mmHg} \text {. For diabetes, CV disease, } \\
\text { and chronic kidney disease, systolic blood pressure }<130 \mathrm{mmHg} \text { and diastolic bloo } \\
\text { pressure }<80 \mathrm{mmHg} \text {. }\end{array}$} \\
\hline \multicolumn{3}{|c|}{$\begin{array}{l}\text { ADP III = Adult Treatment Panel; BMI= body mass index; } C I=\text { confidence interval; } \\
C V=\text { ardiovascular } ; E S H / E S C=\text { European Society of Hypertension } / \text { European } \\
\text { Society of Cardiology; EuroQoL=European Quality of Life; } g \mathrm{gm} / \text { day = gram per } \\
\text { day; } H T N=\text { hypertension; } \mathrm{kg} / \mathrm{m}^{2}=\text { kilogram per square meter } ; \text { min = minute; } \\
\text { mmHg = millimeter per mercury; } S D=\text { standard deviation. }\end{array}$} \\
\hline
\end{tabular}

adherence $>80 \%$, there was a greater proportion of patients with nonadherence that had (a) cardiovascular risk (CVR) $\geq 20 \%$, (b) 5 or more medications, (c) HTN therapy with LPCT, (c) more than 1 pill for HTN, and (d) a good perception of QoL. These variables were statistically significant $(P<0.05)$. 


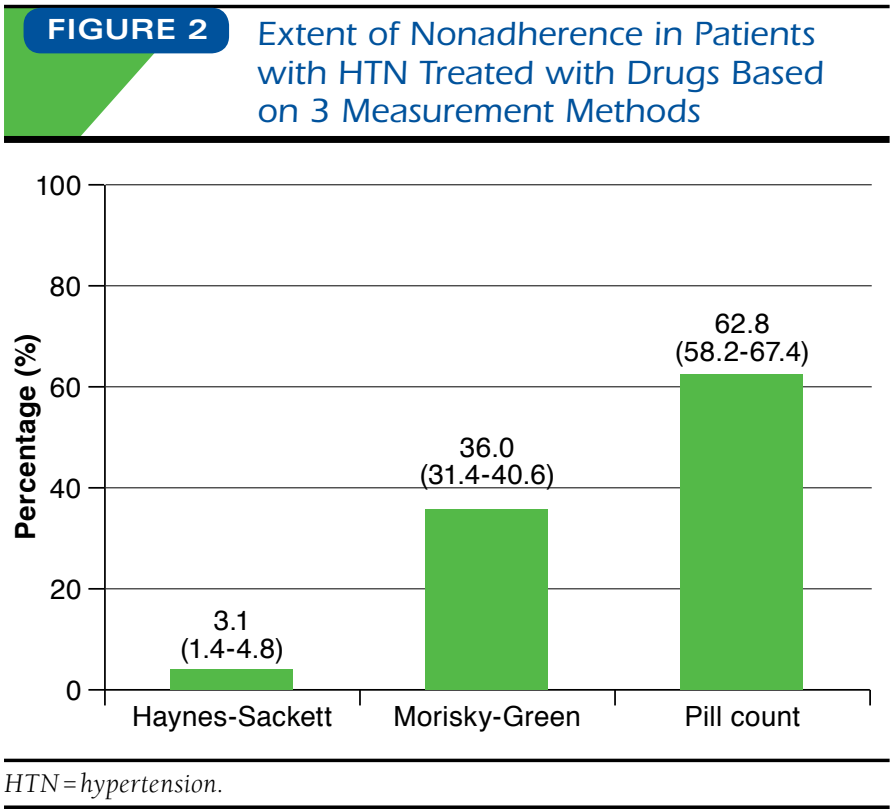

According to the bivariate analysis of the association of quantitative variables with nonadherence as measured by pill count (nonadherence criterion $<80 \%$ ), there was a greater proportion of patients with nonadherence taking more medications for HTN in terms of number of pills and/or number of active agents.

\section{Multivariate Model}

The model was highly significant $(P<0.001)$, explaining $15.7 \%$ of variability. After adjusting for other confounders, 3 variables were found associated with nonadherence (Table 3):

- The years of known HTN $(P=0.005)$ decreased nonadherence (odds ratio $[\mathrm{OR}]=0.962,95 \% \mathrm{CI}=0.937-0.988$ ).

- HTN therapy with LPCT $(P<0.001)$ increased nonadherence. Thus, taking a greater number of pills for HTN increased nonadherence ( $\mathrm{OR}=4.099,95 \% \mathrm{CI}=2.494-6.757)$.

- Good perception of QoL $(P=0.001)$ increased nonadherence $(\mathrm{OR}=1.276,95 \% \mathrm{CI}=1.109-1.471)$.

\section{Discussion}

The characteristics of the patient sample in our study indicated that patients had a mean age of 64 years, with a slight predominance of women and with coexisting CVR factors. The predominant cardiovascular factors were obesity, dyslipidemia, diabetes, physical inactivity, metabolic syndrome, and a high CVR. These factors are consistent with other studies conducted in Spain. ${ }^{26-29}$ Most of the subjects were polymedicated patients with multiple chronic pathologies. In our study, patients with high CVR, who require more BP control, had a high percentage of antihypertensive treatment using MONO (44.2\%) and a low percentage using FDCT (16.5\%). Nevertheless, guidelines

\begin{tabular}{|c|c|c|c|c|c|}
\hline & \multicolumn{5}{|c|}{$\begin{array}{l}\text { Comparison of Different Methods for } \\
\text { Measuring Nonadherence }\end{array}$} \\
\hline & & \multicolumn{3}{|c|}{ Pill Count } & \multirow[b]{2}{*}{ Total } \\
\hline & & Nona & ierence & Adherence & \\
\hline \multirow{3}{*}{$\begin{array}{l}\text { Haynes- } \\
\text { Sackett, } \\
\text { n (\%) }\end{array}$} & Nonadherence & 8 & $(3.0)$ & $5 \quad(3.2)$ & 13 \\
\hline & Adherence & 255 & (97.0) & $151 \quad(96.8)$ & 406 \\
\hline & Total & 263 & $(100.0)$ & $156(100.0)$ & 419 \\
\hline
\end{tabular}

Note: Sensitivity $=0.03$; specificity $=0.97$; positive predictive value $=0.62$; and negative predictive value $=0.37$.

Kappa Index $=-0.001$ (95\% CI=0.076-0.074); poor concordance; chi square $=0.01$, $P=0.92$.

\begin{tabular}{|c|c|c|c|c|}
\hline & \multicolumn{2}{|c|}{ Pill Count } & \multirow[b]{2}{*}{ Total } \\
\hline & & Nonadherence & Adherence & \\
\hline \multirow{3}{*}{$\begin{array}{l}\text { Morisky- } \\
\text { Green, } \\
\mathrm{n}(\%)\end{array}$} & Nonadherence & $94 \quad(35.7)$ & $57(36.5)$ & 151 \\
\hline & Adherence & $169 \quad(64.3)$ & $99 \quad(63.5)$ & 268 \\
\hline & Total & $263(100.0)$ & $156(100.0)$ & 419 \\
\hline
\end{tabular}

Note: Sensitivity $=0.36$; specificity $=0.63$, positive predictive value $=0.62$; and negative predictive value $=0.37$.

Kappa Index $=-0.007$ (95\% CI=0.096-0.082); poor concordance; chi square $=0.03$, $P=0.86$.

$C I=$ confidence interval

advise prescribing a combination of drugs and in FDCT, for patients with high CVR, since simplification of treatment promotes adherence. ${ }^{22,23,30,31}$

In our study, 32\% of patients perceived an acceptable QoL, and this perception is associated with nonadherence. This could be because these patients did not perceive the vascular risk they have, since HTN is asymptomatic. So, strategies involving motivation, information, and developing attitudes such as active participation in self-monitoring and in disease treatment should be considered. ${ }^{5}$

\section{Prevalence of Nonadherence}

Based on the pill count method, almost 2 out of 3 hypertensive patients in our study failed to comply with drug treatment. In considering our results, we look to Haynes et al., ${ }^{16}$ who coined the "rule of thirds" in chronic medication, which states that a third takes medication regularly, a third sometimes, and a third almost never. Nevertheless, other Spanish studies have found a lower proportion of nonadherence. Puigventós et al. ${ }^{8}$ measured $53.6 \%$ nonadherence by pill count; Márquez et al. ${ }^{9}$ also measured by pill counts or medication event monitoring system (MEMS) and found 32.53\% nonadherence. Other studies such as Puras et al. $(2001)^{32}$ found $55.2 \%$ nonadherence, close to that obtained in our study, and Garcia Navarro et al. (2001) $)^{33}$ found a nonadherence rate of $40 \%$. In community pharmacy, the study by Bofil et al. (2006) $)^{34}$ stands out, with a nonadherence rate of $49 \%$, as well as the study by Fikri-Benbrahim et al. $(2013)^{35}$ with a rate of $13.5 \%$. In addition, Baena-Díez et al. $(2011)^{36}$ found a nonadherence rate of $51.3 \%$ using the prescription register $(95 \% \mathrm{CI}=44.3 \%-58.3 \%)$ and $15.4 \%(95 \%$ 


\begin{tabular}{|c|c|c|c|}
\hline \multirow[b]{2}{*}{ Variable } & $\begin{array}{l}\text { Logistic Re } \\
\text { Assess Varia } \\
\text { Nith Nonac } \\
\text { nsive Drug }\end{array}$ & $\begin{array}{l}\text { gression } \\
\text { bles } \\
\text { erence to } \\
\text { Therapy }\end{array}$ & \\
\hline & Adjusted OR & $95 \% \mathrm{CI}$ & $P$ Value \\
\hline \multicolumn{4}{|l|}{ Sex } \\
\hline Male & Reference & & \\
\hline Female & 1.46 & $0.95-1.97$ & 0.140 \\
\hline Age & 1.02 & $51.30-60.90$ & 0.059 \\
\hline Evolution of HTN (years) & 0.96 & $0.94-0.99$ & 0.005 \\
\hline CV risk $(>20 \%)$ & 1.09 & $0.73-1.46$ & 0.625 \\
\hline Metabolic syndrome & 1.43 & $0.90-1.96$ & 0.185 \\
\hline $\mathrm{BMI}\left(>30 \mathrm{~kg} / \mathrm{cm}^{2}\right)$ & 1.00 & $0.96-1.05$ & 0.959 \\
\hline Diabetes mellitus & 1.22 & $0.62-1.83$ & 0.510 \\
\hline Dyslipidemia & 1.15 & $0.59-1.72$ & 0.616 \\
\hline SBP (> $140 \mathrm{mmHg})$ & 0.99 & $0.98-1.01$ & 0.416 \\
\hline DBP (>90 mmHg) & 1.03 & $1.00-1.06$ & 0.026 \\
\hline Total drugs & 0.90 & $0.75-1.06$ & 0.229 \\
\hline Total pills & 0.96 & $0.86-1.07$ & 0.489 \\
\hline Total drugs for HTN & 1.01 & $-0.46-2.48$ & 0.989 \\
\hline Total pills for HTN & 1.17 & $0.57-1.78$ & 0.604 \\
\hline Total active agents for HTN & 1.11 & $0.18-2.04$ & 0.826 \\
\hline \multicolumn{4}{|l|}{ HTN treatment } \\
\hline Fixed-dose combination therapy & Reference & & \\
\hline Loose-pill combination therapy & 4.09 & $2.50-6.80$ & $<0.001$ \\
\hline Number of diseases & 1.03 & $0.99-1.07$ & 0.942 \\
\hline Good QoL (5 points in EuroQol-5D) & 1.28 & $1.11-1.47$ & 0.001 \\
\hline \multicolumn{4}{|c|}{$\begin{array}{l}B M I=\text { body mass index; } C I=\text { confidence interval; } C V=\text { cardiovascular; } D B P=\text { dia- } \\
\text { stolic blood pressure; EuroQol = European } Q u a l i t y \text { of Life survey; } H T N=\text { hyperten- } \\
\text { sion; } \mathrm{kg} / \mathrm{m}^{2}=\text { kilogram per cubic meter; } m \mathrm{mHg}=\text { millimeter of mercury; OR =odds } \\
\text { ratio; } Q \mathrm{QL}=\text { = quality of life; } S B P=\text { systolic blood pressure. }\end{array}$} \\
\hline
\end{tabular}

$\mathrm{CI}=10.3 \%-20.4 \%)$ when using the Morisky-Green test. ${ }^{17}$ It should be noted that some of these were intervention studies, and different methodological approaches were used. These factors could explain the different results of drug nonadherence prevalence obtained.

Outside Spain, other studies reported similar data to those found in our study. According to the 2011 NICE Guidelines, ${ }^{37}$ it was estimated that between $50 \%-80 \%$ of patients with HTN do not take all their prescribed medications. Other studies (Table 4) show varying results, from $7.5 \%$ to $91 \%{ }^{16,38-50}$ These study periods range from the late 1970s to the 2000s, and the methodologies used include pill count and other MEMS.

The variation seen in these studies relates to differences in study groups, duration of follow-up, and drug regimens used in different studies. Another source of variation that could explain the differences in rates of adherence is the method used to measure adherence. Examples of methods used include calculating percentage of pills taken in a specific time period, percentage of patients taking $80 \%$ of their pills, improvement in number of pills taken, dropouts from treatment and follow-up, and missed appointments. ${ }^{7}$ Nevertheless, in most of these studies, nonadherence for HTN medications is very high, and this

\begin{tabular}{|c|c|c|}
\hline TABLE 4 & \multicolumn{2}{|c|}{$\begin{array}{l}\text { Quantification of Drug Nonadherence } \\
\text { in HTN in International Studies }\end{array}$} \\
\hline Author & Year of Publication & $\begin{array}{c}\text { Nonadherence } \\
\text { Percentage }\end{array}$ \\
\hline Sackett ${ }^{38}$ & 1975 & $45 \%$ \\
\hline Logan 39 & 1979 & $51 \%$ \\
\hline Haynes 16 & 1980 & $33 \%$ \\
\hline Enlund $^{41}$ & 1982 & $33 \%$ \\
\hline $\mathrm{Lim}^{42}$ & 1992 & $26 \%$ \\
\hline Mounier-Vehier ${ }^{44}$ & 1998 & 7.5\% (MEMS) \\
\hline $\mathrm{Guo}^{43}$ & 2001 & $36.6 \%$ \\
\hline Baulmann 40 & 2002 & $50 \%$ (MEMS) \\
\hline Schroeder 50 & 2004 & $30 \%-50 \%$ \\
\hline $\mathrm{Lee}^{45}$ & 2006 & $38.8 \%$ \\
\hline Corrao $^{46}$ & 2008 & $50 \%$ at 5 years \\
\hline Vrijens ${ }^{47}$ & 2008 & $50 \%$ at 1 year \\
\hline Mazzaglia48 & 2009 & $91.9 \%$ at 6 months \\
\hline Morgado49 & 2011 & $21 \%-42 \%$ \\
\hline
\end{tabular}

problem must be recognized in clinical practice. Interventions to improve therapeutic adherence are needed that involve not only physicians and nurses but pharmacists as well.

\section{Factors Associated with Nonadherence}

The most important factor seen to be related to nonadherence was therapeutic complexity. ${ }^{50}$ Although there is great variability in the factors identified in different studies, there is no 1 set of variables that completely explains the high percentage of nonadherence.

When performing multivariate analysis, it is noteworthy that very few variables fit the model. Only 3 variables were highly significant in our study (Table 3). The number of years of known HTN was negatively associated with nonadherence, as more years of HTN diminishes nonadherence. Another study found that length of HTN diagnosis was directly associated with nonadherence. ${ }^{51}$ Another found that, for men, shorter length of stay was negatively associated with nonadherence (OR=0.16, 95\% CI=0.05-0.57), and no association between length of stay and nonadherence was found for women. ${ }^{52}$

A variable positively associated with nonadherence was having a good perception of QoL. Perhaps people with good QoL perception are less aware of the disease. Previous studies assessing the relationship between QoL perception and medication adherence have produced different results, which may be due to variation in the techniques used to measure QoL and the study populations examined. ${ }^{53-55}$ Further research is needed to understand the mechanisms that affect adherence to antihypertensive medications.

HTN therapy with LPCT increased nonadherence. Thus, taking a greater number of pills for HTN increased nonadherence. So, simplification of drug regimen, that is, 
using FDCT will be associated with good adherence. This is consistent with the revision by Schroeder et al. (2004) ${ }^{50}$ and with the study by Sicras Mainar et al. (2011). ${ }^{56}$ In a systematic review, Claxton et al. (2001) $)^{57}$ stated that more frequent dosing was associated with lower adherence rates. Adherence was significantly higher for once-daily versus 3-times-daily $(P=0.008)$, once-daily versus 4 -times-daily $(P<0.001)$, and twice-daily versus 4-times-daily regimens $(P=0.001)$. The 2013 ESH/ESC Guidelines ${ }^{58}$ favor the use of combinations of 2 antihypertensive drugs at fixed doses in a single tablet because reducing the number of pills to be taken daily improves adherence and increases the rate of BP control. Other variables such as comorbidity and gender were not associated with adherence.

Studies undertaken to investigate variables influencing treatment adherence have not been able to identify a clear profile of the noncompliant patient, showing differences between studies. ${ }^{50,59,60}$ It has been noted that this profile may change over the therapeutic life of the hypertensive patient because of external circumstances (personal, familiarity, job, social). In our study, it has been shown that the prevalence of therapeutic nonadherence in hypertensive patients could vary widely, depending on the method that has been used, which has implications for clinical practice. In our study, the methods were chosen according to their validity and applicability. Variation between diagnostic methods is usual because some of them have high specificity (few false positives), and others have high sensitivity (few false negatives). In clinical practice, they should be combined.

This study shows that pharmacists can provide information about the causes of nonadherence, which is a first step in dealing with the nonadherence problem. A further step would be pharmacists working together with physicians and nurses in order to improve therapeutic adherence.

\section{Limitations}

This study was conducted in a community pharmacy using patients who go to the pharmacy to collect their medications or to measure their BP. A consecutive population sample instead of a random sample from a list of patients may involve a population selection bias. However, the characteristics of the sample correspond to those usually found in such studies, so no bias was observed in age, sex, or HTN characteristics. ${ }^{4,36}$ Another potential bias could be that patients who choose not to follow their prescriptions after leaving their physicians' offices do not go to the pharmacy to collect their medications. If these patients were included, the proportion of noncompliant patients would be even higher than that found in this study. On the other hand, during the pill count process, patients may feel they are being studied (Hawthorne effect) and become more compliant.

There is no perfect method to measure nonadherence. Questionnaires and clinical interviews are widely used for measuring adherence, some with low validity, but the closest to the ideal method is pill count. ${ }^{12,60}$ This method requires more effort because several visits are needed, which is why this method is less often used than others. In our study, 1 person conducted the interviews to minimize bias from different observers.

Another information or measurement bias is failure by the patient to provide all the requested medications. Patients were asked to bring all medications that they were taking. We asked about any forgotten medication, inviting them to bring it after the visit or calling them at home after the visit to avoid losses. Eight subjects failed to bring all antihypertensive medications or were impossible to contact by phone (Figure 1).

\section{Conclusions}

The magnitude of therapeutic nonadherence is important because, based on the pill count method, 2 out of 3 hypertensive patients (62.8\%) who visit the pharmacy are identified as noncompliant with antihypertensive drug therapy. Based on other methods, this proportion changed significantly-36.0\% with the Morisky-Green test and 3.1\% with the Haynes-Sackett test.

Few variables are associated with therapeutic nonadherence: the use of LPCT, perception of a good QoL, and less years of known HTN. Therapeutic adherence might be improved if the causes are identified. This study shows that in addition to physicians and nurses, pharmacists are able to provide information that can better help us to understand nonadherence. Thus, we should use all avenues available to us in order to deal with the issue of nonadherence.

\section{Authors}

ZENEIDA PERSEGUER-TORREGROSA, PhD, is Manager, Community Pharmacy, Petrer, Spain, and Research Assistant, Clinical Medicine Department, Miguel Hernandez University, San Juan de Alicante, Spain. DOMINGO OROZCO-BELTRÁN, $\mathrm{PhD}$, is Assistant Professor of Primary Health Care Research; CONCEPCIÓN CARRATALÁ-MUNUERA, PhD, is Assistant Professor of Primary Care Research; and ADRIANA LOPEZPINEDA, MSc, is Research Assistant, Clinical Medicine Department, Miguel Hernandez University, San Juan de Alicante, Spain. VICENTE F. GIL-GUILLEN, PhD, is Professor of Clinical Medicine, Clinical Medicine Department, Miguel Hernandez University, San Juan de Alicante, Spain, and Director, Research Unit, Elda Hospital, Elda, Spain; SALVADOR PITA-FERNANDEZ, PhD, is Director, Clinical Epidemiology and Biostatistics Unit, University Hospital of A Coruña, A Coruña, Spain; and VICENTE PALLARESCARRATALÁ, PhD, is Manager, Health Surveillance Unit, Unión de Mutuas, Castellón, Spain, and Assistant Professor, Medicine Department, Jaume I University, Castellón, Spain.

AUTHOR CORRESPONDENCE: Zeneida Perseguer-Torregrosa, PhD, Clinical Medicine Department, Miguel Hernandez University, Ctra. Nnal. Alicante-Valencia s/n 03550, San Juan de Alicante, Spain. Tel.: +34.965.919.309; E-mail: zeneidaperseguer@gmail.com. 


\section{Magnitude of Pharmacological Nonadherence in Hypertensive Patients \\ Taking Antihypertensive Medication from a Community Pharmacy in Spain}

\section{DISCLOSURES}

This was an unfunded research study. The authors declare no conflicts of interests.

Concept and design were performed by Perseguer-Torregrosa, OrozcoBeltrán, Gil-Guillen, and Pallarés-Carratalá. Search bibliography was performed by Carratalá-Munuera. Data were collected by Perseguer-Torregrosa. Statistical analyses were performed by Pita-Fernandez. The manuscript was written by Perseguer-Torregrosa, Orozco-Beltrán, Carratalá-Munuera, and Lopez-Pineda and revised by Gil-Guillen, Pallarés-Carratalá, and PitaFernandez. All authors have approved the manuscript for publication.

\section{REFERENCES}

1. Lewington S, Clarke R, Qizilbash N, Peto R, Collins R; Prospective Studies Collaboration. Age-specific relevance of usual blood pressure to vascular mortality: a meta-analysis of individual data for one million adults in 61 prospective studies. Lancet. 2002;360(9349):1903-13.

2. Lloyd-Jones D, Adams RJ, Brown TM, et al; American Heart Association Statistics Committee and Stroke Statistics Subcommittee. Heart disease and stroke statistics: 2010 update: a report from the American Heart Association. Circulation. 2010;121(7):e46-e215

3. Grau M, Elosua R, Cabrera de León A, et al. [Cardiovascular risk factors in Spain in the first decade of the 21st Century, a pooled analysis with individual data from 11 population-based studies: the DARIOS study]. Rev Esp Cardiol. 2011;64(4):295-304. [Article in Spanish]. Available at: http://www. revespcardiol.org/en/linkresolver/factores-riesgo-cardiovascular-espanaprimera/90002079/. Accessed October 2, 2014

4. Llisterri JL, Rodriguez-Roca GC, Escobar C, et al.; Working Group of Arterial Hypertension of the Spanish Society of Primary Care Physicians Group HTA SEMERGEN; PRESCAP 2010 investigators. Treatment and blood pressure control in Spain during 2002-2010. J Hypertens. 2012;30(12):2425-31

5. Trevisol DJ, Moreira LB, Kerkhoff A, Fuchs SC, Fuchs FD. Health-related QoL and hypertension: a systematic review and meta-analysis of observational studies. J Hypertens. 2011;29(2):179-88.

6. Pittman DG, Tao Z, Chen W, Stettin GD. Antihypertensive medication adherence and subsequent healthcare utilization and costs. Am J Manag Care. 2010;16(8):568-76

7. World Health Organization. Adherence to long-term therapies: evidence for action. 2003. Available at: http://whqlibdoc.who.int/publications/2003/9241545992.pdf. Accessed October 2, 2014

8. Puigventós Latorre F, Llodrà Ortolà V, Vilanova Boltó M, et al. [Adherence with hypertension treatment: 10 years of publications in Spain]. Med Clin (Barc).1997;109(18):702-06. [Article in Spanish]

9. Márquez Contreras E, Gil Guillén V, Casado Martínez JJ, et al. [Analysis of studies published on hypertension treatment non-adherence in Spain between 1984 and 2005]. Aten Primaria. 2006;38(6):325-32. [Article in Spanish]. Available at: http://zl.elsevier.es/es/revista/atencion-primaria-27/ analisis-los-estudios-publicados-incumplimiento-terapeutico-tratamiento13093369-originales-2006. Accessed October 2, 2014

10. Steele DJ, Jackson TC, Gutmann MC. Have you been taking your pills? The adherence-monitoring sequence in the medical interview. J Fam Pract. 1990;30(3):294-99.

11. Rand C. Issues in the measurement of adherence. In: Schron E, Ockene J, Shumaker S, eds. Handbook of Health Behavior Change. New York: Springer Publishing Co.; 1990:102-10.

12. Choo PW, Rand CS, Inui TS, et al. Validation of patient reports, automated pharmacy records, and pill counts with electronic monitoring of adherence to antihypertensive therapy. Med Care. 1999;37(9):846-57.

13. Krousel-Wood M, Thomas S, Muntner P, Morisky D. Medication adherence: a key factor in achieving blood pressure control and good clinical outcomes in hypertensive patients. Curr Opin Cardiol. 2004;19(4):357-62.
14. International Pharmaceutical Federation. Declaración de las normas profesionales de FIP. El papel del farmacéutico en la estimulación de la adherencia a los tratamientos de largo plazo. Sydney, Australia. September 2003. Available at: https://www.fip.org/www/uploads/database_file. php?id=220\&table_id=. Accessed October 2, 2014.

15. Badia X, Roset M, Montserrat S, Herdman M, Segura A. [The Spanish version of EuroQol: a description and its applications. European Quality of Life scale]. Med Clin (Barc). 1999;112(Suppl 1):79-85. [Article in Spanish].

16. Haynes RB, Taylor DW, Sackett DL, Gibson ES, Bernholz CD, Mukherjee J Can simple clinical measurements detect patient nonadherence? Hypertension. 1980;2(6):757-64.

17. Morisky DE, Green LW, Levine DM. Concurrent and predictive validity of a self-reported measure of medication adherence. Med Care. 1986;24(1):67-74.

18. Salas-Salvadó J, Rubio MA, Barbany M, Moreno B; Grupo Colaborativo de la SEEDO. [SEEDO 2007 Consensus for the evaluation of overweight and obesity and the establishment of therapeutic intervention criteria]. Med Clin (Barc). 2007;128(5):184-96. [Article in Spanish].

19. Toledo E, Hu FB, Estruch R, et al. Effect of the Mediterranean diet on blood pressure in the PREDIMED trial: results from a randomized controlled trial. BMC Med. 2013;11:207.

20. Córdoba R, Cabezas C, Camarelles F, et al. [Life style recommendations] Aten Primaria. 2012;44(Suppl 1):16-22. [Article in Spanish].

21. Marín R, de la Sierra A, Armario P, et al. [2005 Spanish guidelines on diagnosis and treatment of arterial hypertension]. Med Clin (Barc). 2005;125(1):24-34. [Article in Spanish].

22. European Society of Hypertension-European Society of Cardiology Guidelines Committee. 2003 European Society of Hypertension-European Society of Cardiology guidelines for the management of arterial hypertension. J Hypertens. 2003;21(6):1011-53.

23. Grupo de Trabajo para el Tratamiento de la Hipertensión Arterial de la Sociedad Europea, Sociedad Europea de Cardiología, Mancia G, et al. [ESH/ ESC 2007 Guidelines for the management of arterial hypertension]. Rev Esp Cardiol. 2007;60(9):968.el-94. [Article in Spanish].

24. Sabater-Hernández D, de la Sierra A, Sánchez-Villegas P, et al. Magnitude of the white-coat effect in the community pharmacy setting: the MEPAFAR study. Am J Hypertens. 2011;24(8):887-92.

25. Agencia Española de Protección de Datos. Ley Orgánica 15/1999, de 13 de diciembre, de Protección de Datos de Carácter Personal (BOE núm. 298, 14-12-1999, pp. 43088-43099) [Organic Law, 15/1999, for Protection of Data of Personal Nature]. Available at: http://www.agpd.es/portalwebAGPD/english_resources/regulations/index-iden-idphp.php. Accessed October 17, 2014.

26. Torres A. Fité B. Gascón P, et al. [Effectiveness of a pharmaceutical care program in the improvement of blood pressure monitoring in poorly controlled hypertensive patients. PressFarm Study]. Hipertensión. 2010;27:13-22. [Article in Spanish].

27. Márquez Contreras E, de Rivas Otero B, Divisón Garrote JA, Sobreviela Blázquez E, Luque Otero M. [Are hypertensive patients managed in primary care well evaluated and controlled? HICAP Study]. An Med Interna. 2007;24(7):312-16. [Article in Spanish].

28. Márquez Contreras E, Coca A, de la Figuera von Wichmann M, et al. [Cardiovascular risk profile of uncontrolled hypertensive patients. The Control-Project study]. Med Clin (Barc). 2007;128(3):86-91. [Article in Spanish].

29. Galarza CR, Alfie J, Waisman GD, et al. Diastolic pressure underestimates age-related hemodynamic impairment. Hypertension. 1997;30(4): 809-16.

30. Chobanian AV, Bakris GL, Black HR, et al. The Seventh Report of the Joint National Committee on Prevention, Detection, Evaluation, and Treatment of High Blood Pressure: the JNC 7 report. JAMA. 2003;289(19):2560-72. Available at: http://www.nhlbi.nih.gov/guidelines/ hypertension/jnc7full.pdf. Accessed October 2, 2014 
31. Coca A, Bertomeu V, Dalfó A, et al. [Blood pressure self-measurement: Spanish consensus document]. Nefrologia. 2007;27(2):139-53. [Article in Spanish]. Available at: http://www.revistanefrologia.com/revistas/P1-E257/ P1-E257-S136-A4570.pdf. Accessed October 2, 2014

32. Puras A, Massó J, Artigao LM, et al. [Compliance with drug treatment and degree of control in hypertension: epidemiological study. Who meets less: the patient or the doctor?] Med Clin (Barc). 2001;116(Suppl 2):101-04. [Article in Spanish].

33. García Navarro MD, Orozco Beltrán D, Gil Guillén V, Carratalá Munuera C, Terol Moltó C, Merino Sánchez J. [Relationship between drug compliance and degree of control in patients with hypertension, diabetes or dyslipidemia]. Med Clin (Barc). 2001;116(Suppl 2):141-46. [Article in Spanish].

34. Bofill C, Valenti MJ, Palmer JL, et al. Intervención sobre uso racional del medicamento:experiencia piloto en centros de atención primaria y las farmacias de su entorno. Pharm Care Esp. 2006;8(5):209-17.

35. Fikri-Benbrahim N, Faus MJ, Martínez-Martínez F, Sabater-Hernández D. Impact of a community pharmacists' hypertension-care service on medication adherence. The AFenPA study. Res Social Adm Pharm. 2013;9(6):797-805.

36. Baena-Díez JM, Gómez-Fernández C, Vilató-García M, Vásquez-Lazo EJ, Byram AO, Vidal-Solsona M. [A prescription register incorporated into computerized medical records for patients with hypertension: a new instrument to evaluate medication adherence]. Aten Primaria. 2011;43(7):336-42. [Article in Spanish].

37. Krause T, Lovibond K, Caulfield M, McCormack T, Williams B; Guideline Development Group. Management of hypertension: summary of NICE guidance. BMJ. 2011;343:d4891.

38. Sackett DL, Haynes RB, Gibson ES, et al. Randomised clinical trial of strategies for improving medication adherencein primary hypertension. Lancet. 1975;1(7918):1205-07.

39. Logan AG, Milne BJ, Achber C, Campbell WP, Haynes RB. Work-site treatment of hypertension by specially trained nurses. A controlled trial. Lancet. 1979;2(8153):1175-78.

40. Baulmann J, Düsing R, Vetter H, Mengden T. [Therapy resistant hypertension-significance of electronic compliance monitoring]. Dtsch Med Wochenschr. 2002;127(45):2379-82. [Article in German].

41. Enlund H. Measuring patient compliance in antihypertensive therapysome methodological aspects. J Clin Hosp Pharm. 1982;7(1):43-51.

42. Lim TO, Ngah BA, Rahman RA, et al. The Mentakab hypertension study project. Part V-drug adherence in hypertensive patients. Singapore Med J. 1992;33(1):63-66.

43. Guo H, He H, Jiang J. [Study on the compliance of antihypertensive drugs in patients with hypertension]. Zhonghua Liu Xing Bing Xue Za Zhi. 2001;22(6):418-20. [Article in Chinese]

44. Mounier-Vehier C, Bernaud C, Carré A, Lequeuche B, Hotton JM, Charpentier JC. Compliance and antihypertensive efficacy of amlodipine compared with nifedipine slow-release. Am J Hypertens. 1998;11(4 Pt 1):478-86.

45. Lee JK, Grace KA, Taylor AJ. Effect of a pharmacy care program on medication adherence and persistence, blood pressure and low-density lipoproteincholesterol: a randomized controlled trial. JAMA. 2006;296(21):2563-71.

46. Corrao G, Zambon A, Parodi A, et al. Discontinuation of and changes in drug therapy for hypertension among newly treated patients: a populationbased study in Italy. J Hypertens. 2008;26(4):819-24.
47. Vrijens B, Vincze G, Kristanto P, Urquhart J, Burnier M. Adherence to prescribed antihypertensive drug treatments: longitudinal study of electronically compiled dosing histories. BMJ. 2008;336(7653):1114-17.

48. Mazzaglia G, Ambrosioni E, Alacqua M, et al. Adherence to antihypertensive medications and cardiovascular morbidity among newly diagnosed hypertensive patients. Circulation. 2009;120(16):1598-605.

49. Morgado MP, Morgado SR, Mendes LC, Pereira LJ, Castelo-Branco M. Pharmacist interventions to enhance blood pressure control and adherence to antihypertensive therapy: review and meta-analysis. Am J Health Syst Pharm. 2011;68(3):241-53.

50. Schroeder K, Fahey T, Ebrahim S. Interventions for improving adherence to treatment in patients with high blood pressure in ambulatory settings. Cochrane Database Syst Rev. 2004;(2):CD004804.

51. Li WW, Kuo CT, Hwang SL, Hsu HT. Factors related to medication nonadherence for patients with hypertension in Taiwan. J Clin Nurs. 2012;21 (13-14):1816-24

52. Li WW, Wallhagen MI, Froelicher ES. Hypertension control, predictors for medication adherence and gender differences in older Chinese immigrants. J Adv Nurs. 2008;61(3):326-35.

53. Holt EW, Muntner P, Joyce CJ, Webber L, Krousel-Wood MA. Healthrelated quality of life and antihypertensive medication adherence among older adults. Age Ageing. 2010;39(4):481-87. Available at: http://ageing.oxfordjournals.org/content/39/4/481.long. Accessed October 2, 2014.

54. Trivedi RB, Ayotte B, Edelman D, Bosworth HB. The association of emotional well-being and marital status with treatment adherence among patients with hypertension. J Behav Med. 2008;31(6):489-97.

55. Pippalla RS, Chinburapa V, Duval R, Akula RS. Interrelationships of quality of life, adherence, clinical outcomes and life satisfaction: a crosssectional study on hypertensive geriatrics. J Clin Pharm Ther. 1997;22(5-6): 357-69.

56. Sicras Mainar A, Galera Llorca J, Muñoz Ortí G, Navarro Artieda R. [Influence of compliance on the incidence of cardiovascular events and health costs when using single-pill fixed-dose combinations for the treatment of hypertension]. Med Clin (Barc). 2011;136(5):183-91. [Article in Spanish]

57. Claxton AJ, Cramer J, Pierce C. A systematic review of the associations between dose regimens and medication compliance. Clin Ther. 2001;23(8):1296-310.

58. ESH/ESC Task Force for the Management of Arterial Hypertension. 2013 Practice guidelines for the management of arterial hypertension of the European Society of Hypertension (ESH) and the European Society of Cardiology (ESC): ESH/ESC Task Force for the Management of Arterial Hypertension. J Hypertens. 2013;31(10):1925-38.

59. Krousel-Wood M, Joyce C, Holt E, et al. Predictors of decline in medication adherence: results from the cohort study of medication adherence among older adults. Hypertension. 2011;58(5):804-10. Available at: http://www.ncbi. nlm.nih.gov/pmc/articles/PMC3220657/. Accessed October 2, 2014.

60. Prado JC Jr, Kupek E, Mion D Jr. Validity of four indirect methods to measure adherence in primary care hypertensives. J Hum Hypertens. 2007;21(7):579-84. 